[JERUSALEM] Leading officials in the Israeli government are reacting cautiously to a bill proposing stringent restrictions on the use of genetic information. The bill was passed last week by the Israeli parliament's science committee.

It was submitted by Knesset member Meir Shitrit, based on proposals drawn up by George Annas, professor of public health at Boston University School of Public Health, who has been closely involved in similar legislation in the United States (see Nature 384, 202; 1996).

The bill would grant individuals considerable control over genetic material taken from them for either medical tests or research purposes, and would forbid employers and insurance companies from discriminating on the basis of a person's genetic profile.

But Bracha Rager, chief scientist at the Ministry of Health, calls Shitrit's bill "problematic", arguing that it could prevent doctors from performing important medical tests, and might also act as an obstacle to medical research.

Shitrit complains that, at present, Israel lacks any controls over the way genetic information is handled. "There is no supervision, nolicensing; no one explains to people about the implications of genetic tests, and there is no genetic counselling," he says.

His original bill contained a sweeping provision making all genetic material the property of the donor, who would have the right to demand that such material be destroyed at any time he or she chose.

This provision has been removed from the version that will go to the full Knesset for its first reading. But other provisions would still grant citizens considerable control over any of their genetic material that is likely to be obtained by doctors and researchers.

Shitrit argues that such controls are necessary to prevent the genetic information from being misused. But Rager contends that it is could be detrimental to patients.

For example, she says, someone who has provided genetic material to be tested for either of two genetic markers for a form of cancer, and who then asked for the material to be destroyed, could miss out on a vital test if a third marker were subsequently discovered.

Rager agrees with the provision in Shitrit's bill that genetic material donated for research purposes should be anonymous. But she adds that researchers should still be permitted to know certain basic features of the donor, and fears that the proposed law will prevent scientists from obtaining even these essential data.

Gali Ben-Or, an assistant deputy attorney-general who has been working on the issue of genetic property for the Ministry of
Justice, also believes that Shitrit's proposal is too broad. "Our position is that the bill is not constructed to take into account current legislation," Ben-Or says.

She argues that Israel already has laws dealing with similar issues, such as patients' rights and medical privacy. Ben-Or says it would be better to amend these laws to cover the new questions raised by genetic testing, rather than pass an entirely new law.

She points out, for example, that Israel's national health law guarantees health insurance to all citizens, and therefore there is no fear that an Israeli who has inherited a risky gene would not be able to get health insur- ance. She also said that there might be some forms of employment, such as high-risk jobs involving, for example, exposure to radiation, where a person's genetic predispositions might be a legitimate consideration.

But not everyone agrees. Asa Kasher, who holds a chair in the professional ethics and philosophy of practice at the University of Tel Aviv, and is chairman of the National Research and Development Council's committee of ethics of science and intellectual property, also fears that some of the provisions of Shitrit's bill are too broad. But he accepts that special legislation is necessary.

HaimWatzman

\title{
Swiss databank to start charging for use
}

[MUNICH] The Swiss-Prot protein sequence databank, one of the world's most widely used reference sources on proteins, is introducing a system of licensing for private companies to ensure stable financing and help fund an expansion of its activities. Academic researchers will still be able to use the databank without charge.

Swiss-Prot is a joint enterprise between the newly created Swiss Institute of Bioinformatics and the European Bioinformatics Institute, the Cambridgebased outstation of the European Molecular Biology Laboratory (EMBL).

It is particularly valued by scientists because of the information added to simple translations of publicly available nucleotide sequences through the detailed annotation applied by the database's staff.

Until now, Swiss-Prot has been fully supported by public funding, and has provided a free service to both industry and academic researchers. But it hit a major funding crisis in 1996 when two major grants from the Swiss government were not renewed (see Nature 381, 266; 1996). It only managed to avert closure through a campaign for interim support, and is currently running on support from Swiss funding agencies.

Amos Bairoch, who founded Swiss-Prot in 1986, says it resisted buy-out offers from several commercial companies because he and his colleagues were concerned that commercial interests might be reluctant to continue maintaining open access to academic researchers.

Instead they are planning to develop a more stable funding strategy under which Swiss-Prot would receive half of its funding from public sources and half through licence fees from private companies.

Bairoch helped to set up the Swiss Institute of Bioinformatics from five Geneva-based bioinformatics research groups, including those already involved in Swiss-Prot. It is independent of the university system.

As such, it is entitled to receive direct funding from the government without depending on university grant money. The government has already indicated that it considers Swiss-Prot a funding priority.

Bairoch says he also encouraged the creation last November of an independent Geneva-based company, GeneBio, which, in addition to its core business of developing high-quality specialized protein databases, will handle the administration of SwissProt's licensing scheme.

Fees will range from US $\$ 2,500$ for small start-up companies to US\$9,000 for large companies. Pharmaceutical companies are used to paying this level of fee for databases, says Bairoch.

Fotis Kafatos, director-general of EMBL, emphasizes that the decision to impose licence fees will have no repercussions for nucleotide databases at the European Bioinformatics Institute, which are repositories of raw data. He points out that Swiss-Prot licensees will be paying for the "very labour-intensive expert curation".

The new funding system will allow Swiss-Prot to expand. At present the database includes 73,000 proteins, but an additional stockpile of 150,000 'virtual proteins' - those whose sequence is deduced from nucleotide information, but have not been functionally analysed - are waiting in the wings to be worked on.

Swiss-Prot staff stress that academics will continue to be exempt from charges. 'Grey' academic research areas involving small university-based start-up companies or industrial collaborators will be negotiated on a case-by-case basis, says Bairoch, adding that Swiss-Prot does not wish to interfere with academic enterprise. 